\title{
Nove Noites \& Lord Jim: uma leitura intertextual do homem moderno
}

\section{Wilson Ponciano Junior*}

Resumo: Esse ensaio explora como "Lord Jim" Abstract: This essay explores how Joseph Conrad's (1900), de Joseph Conrad, está relacionado à "Nove "Lord Jim" (1900) is related to "Nine Nights" ("Nove noites" (2002), de Bernardo Carvalho, através da Noites" (2002)), by Bernardo Carvalho, finding a recontextualização de conceitos de Antonio Candido recontextualization for terms of Antonio Candido's em "Catástrofe e sobrevivência", um estudo sobre "Catastrophe and survival" ("Catástrofe e aquele romance. sobrevivência"), a study about the former novel.

Palavras-chave: Bernardo Carvalho; Joseph Conrad; Keywords: Bernardo Carvalho; Joseph Conrad; globalização; modernidade. globalization; modernity.

- A falar verdade, Stein, eu vim para descrever um espécime, eu também...

- Uma borboleta? - perguntou-me, com uma vivacidade incrédula e alegre.

- Não, não é nada de tão perfeito assim... Trata-se um homem....

(Lord Jim - Joseph Conrad)

Se as coisas que tenho a dizer estão todas pela metade, e podem soar insignificantes aos ouvidos de outra pessoa, é porque estão à sua espera para fazer sentido. Só você pode entender o que quero dizer, pois tem a chave que me falta. Só você tem a outra parte da história.

(Nove noites - Bernardo Carvalho)

Não há como negar que a globalização segue par e passo o conceito de pósmodernidade, abrindo cada vez mais espaço na crítica literária. Estudar a representação ficcional do mundo contemporâneo pressupõe mergulhar num emaranhado labirinto de identidades. "As tentativas de contar histórias ainda mais grandiosas e dramáticas começam a surgir, agora que as mais antigas estão se desgastando: histórias de choques de sociedades

\footnotetext{
* Mestrando no Programa de Pós-Graduação em Letras da Universidade do Vale do Rio dos Sinos (UFRGS). Especialista em Literatura Brasileira pela Universidade do Vale do Rio dos Sinos (UNISINOS). E-mail: poncianojr@uol.com.br
} 
incomunicáveis, morais contraditórias e visões de mundo incomensuráveis." (GEERTZ, 2001, p. 194)

Por esse motivo, a revisão das narrativas (e sua fortuna crítica) que antecedem a obra de um autor que continua a escrever é primordial para levantar algumas hipóteses, ainda que breves e transitórias. Um estudo intertextual permitiria, portanto, entender o nicho em que uma obra literária se inscreve e até mesmo modificar a filiação de uma antecessora a determinado contexto; principalmente se forem consideradas produções afastadas temporal, espacial e culturalmente.

É sob essa perspectiva que se deve entender as palavras de Leyla Perrone-Moisés, ao investigar o processo relacional de textos canônicos e modernos, que destacam positivamente que: "no decorrer do século XX, não apenas houve acréscimos ao cânone, mas procedeu-se a uma revisão do passado, comprovando as afirmações de Eliot (o passado é alterado pelo presente) e de Borges (o escritor cria seus precursores)". (PERRONE-MOISÉS, 1998, p. 174)

A aproximação entre dois textos pode vir expressa literalmente num deles ou dar-se por uma natureza em comum (que não se distancia muito da primeira idéia). A boa execução desse movimento, todavia, deve não se firmar como ratificação de uma obviedade ou como plágio. Deve ser ainda mais que meramente a reprodução de ideologias. Antes, necessita privilegiar a renovação ou o contraste dessas ideologias.

Em Nove noites (2002), de Bernardo Carvalho, romance vencedor do Prêmio Portugal Telecom 2003, por exemplo, uma das personagens apresenta certa obsessão por Lord Jim (1900), de Joseph Conrad. O fato parece irrelevante diante dos acontecimentos da complexa narrativa, porém, numa leitura intertextual, pode revelar muito sobre o comportamento de muitas personagens da narrativa, e, por extensão, do homem contemporâneo. O escritor brasileiro é reconhecido como hábil construtor de narrativas em que a dúvida impera e as identidades individual e nacional são colocadas em cheque.

A fragilidade e a ambigüidade da vida moderna são ilustradas, especialmente, pelos narradores em primeira pessoa especialmente nesse romance; mas também nos demais do autor: Os bêbados e os sonâmbulos (1996), Teatro (1998) e Mongólia (2003). Nesse sentido, há identificação entre o texto bernardino e o conradiano, como sintetizado por Miklós Szalbolcsi:

Viagens de navio, paisagens exóticas, aventuras, acontecimentos selvagens e violentos constituem as nervosas histórias externas desse escritor de origem polonesa, que aprendeu a língua inglesa apenas com dezenove anos. Mas tudo isso é exterioridade e simples pretexto para descrever o comportamento humano. O que o motiva é o funcionamento dos instintos, o mecanismo do poder e o comportamento muitas vezes irracional das multidões e grupos. 
Afirma-se a respeito de Conrad, com acerto, que foi o escritor dos marinheiros e não dos mares. (SZALBOLCSI, 1987, p. 23)

Essa síntese, portanto, ultrapassa muitas leituras redutoras, que vêem no autor somente marcas de exotismo e imperialismo. "Catástrofe e sobrevivência", ensaio de Antonio Candido, anterior ao pós-colonialismo (a primeira edição de Tese e antítese é de 1963), mas atento aos movimentos sociais, corrobora SZALBOLCSI (1987). Não nega o gosto de Joseph Conrad pelo pitoresco, mas aponta que, no decorrer das várias obras,

sua preocupação foi sempre, e cada vez mais, apresentar uma visão dramática do homem, independente das circunstâncias de lugar. [Essas circunstâncias são] o meio propício à formação e eclosão dalguns dos seus temas mais reveladores: o isolamento, a ocasião, o homem surpreendido, dispostos à volta da preocupação fundamental com o ato, em que para ele se espelha realmente o homem.(CANDIDO, 2000, p. 59-62)

Lord Jim é a história de um homem do mar à espera do momento exato de agir, posicionar-se diante da vida, mas que, pela insegurança, acaba sempre deixando as oportunidades passarem. Ao abandonar o posto em momento de perigo, o oficial da marinha prepara sua sentença. É destituído e passa a esconder-se dos outros homens. O desconforto causado pela indefinição, pelo auto-boicote e pela dificuldade de assumir um erro provoca na personagem-título apreensão, medo e angústia, transferidas para atualidade sob o signo de depressão. Daí a relevância do ato como fator determinante e determinado pelos demais temas.

Quando investigados no romance de Bernardo Carvalho, esses temas (isolamento, ocasião, homem surpreendido e ato) revelam que não só a personagem do americano senil e moribundo, cuja identidade é desconhecida de todos, tem a ver com o texto conradiano, mas sim todas as outras personagens masculinas. A narrativa é montada sob o efeito de uma caixa de espelhos. Mesmo sem se conhecerem, as personagens interferem nas vidas umas das outras. As ações são reiteradas e ratificadas o tempo todo, como n'As horas, de Michael Cunningham. A questão dos gêneros é fundamental na obra bernardina. Em Nove noites, porém, as mulheres desempenham papel secundário. A discussão é o destino dos homens. Sintomaticamente, são dois deles que assumem a narração e se intercalam no relato das causas e conseqüências do suicídio de um outro, o antropólogo Buell Quain.

A morte do americano em terras brasileiras enquanto trabalhava com uma tribo indígena não é ficcional. E provocou até mesmo um conflito diplomático entre os países envolvidos. Essa informação é dada por um dos narradores, que não se nomeia, mas que se permite identificar como jornalista, funcionando como alter ego de Bernardo. Há nesse sentido inúmeras semelhanças na biografia do autor e a criada para o narrador, essa situação 
de dúvida quanto à identificação do autor no texto é fomentada por uma estratégia discursiva que, cada vez mais, torna-se freqüente na modernidade. Assim como, o romance-repórter tem se popularizado.

No início, o tom do relato desse narrador é jornalístico, fundamentado em documentos aos quais supostamente teria tido acesso, inclusive através de entrevistas com pessoas reais que teriam conhecido de fato o antropólogo. À medida que o romance avança, no entanto, a narração se torna voltada não mais para o caso do suicídio, mas sim para a explicação dos motivos íntimos da personagem em elucidar a morte. O porquê da morte de Buell Quain nunca ficou esclarecido, exceto para essa personagem que chega às últimas conseqüências na investigação.

O outro narrador é identificado pelo primeiro como Manoel Perna, um engenheiro de Carolina, cidade mais próxima da aldeia indígena onde o pesquisador ficou até a fatalidade. Antes de se matar, o americano teria escrito cartas a familiares e aos responsáveis por sua estadia no Brasil. Manoel e Quain seriam amigos, e este teria confiado ao outro a missão de entregar as cartas, além de lhe escrever uma com confissões acerca do motivo de seu ato. Essa narração é epistolar. Quase no final do romance, o narrador-jornalista revela ter conseguido através dos filhos do engenheiro acesso a cartas escritas por ele, na ânsia de dividir com alguém (que para o próprio Manoel não estava evidente quem seria) suas impressões sobre Quain. As cartas são dirigidas a uma pessoa muito íntima do americano, mas que é desconhecida pelo brasileiro.

Acerca dos narradores de Nove noites, Bernardo revela em entrevista à revista

\title{
Entrelivros que:
}

\begin{abstract}
Houve uma pesquisa sobre fatos reais, que precedeu a escrita, coisa que não costumava fazer. Desse ponto de vista, a linguagem mais jornalística, ou com aparência de uma linguagem mais direta, se explica. É a linguagem do relato. Por outro lado, logo que comecei a fazer a pesquisa, deparei com as cartas de um sujeito, Manoel Perna, um homem do sertão, que havia conhecido Quain nos meses que precederam o seu suicídio, e logo percebi que ele tinha que ser um dos narradores, porque era a pessoa mais próxima do antropólogo quando ele se matou, o único que teria podido revelar alguma coisa sobre o suicídio do amigo, se ainda estivesse vivo. Isso me possibilitou brincar também com um outro registro, mais rebuscado, mais florido, que é o contrário de tudo a que eu tinha me permitido até então. Transformando em narrador um homem da província que queria escrever belas cartas, eu podia dar livre curso às metáforas e às belas frases, coisa que sempre me causou o maior horror. Então, por razões que foram próprias daquele livro e daquele processo, houve uma espécie de mudança em relação à linguagem dos livros anteriores, ao mesmo tempo pra os dois extremos opostos: de um lado, o relato jornalístico e, do outro, o beletrismo. (LAUB, 2006, p. 24)
\end{abstract}

O mal que devorou o americano é o mesmo que impulsiona ambos os homens, da província e da metrópole, a buscarem uma explicação para a vida. É interessante notar, portanto, o modo como eles, respectivamente, iniciam suas narrações: 
Isto é para quando você vier. É preciso estar preparado. Alguém terá que preveni-lo. Vai entrar numa terra em que a verdade e a mentira não têm mais os sentidos que o trouxeram até aqui. Pergunte aos índios. Qualquer coisa. O que primeiro lhe passar pela cabeça. E amanhã, ao acordar, faça de novo a mesma pergunta. E depois de amanhã, mais uma vez. Sempre a mesma pergunta. E a cada dia receberá uma resposta diferente. A verdade está perdida entre todas as contradições e os disparates. Quando vier à procura do que o passado enterrou, é preciso saber que estará às portas de uma terra em que a memória não pode ser exumada, pois o segredo, sendo o único bem que se leva para o túmulo, é também a única herança que se deixa aos que ficam, como você e eu, à espera de um sentido, nem que seja pela suposição do mistério, para acabar morrendo de curiosidade. (CARVALHO, 2004, p. 7)

Ninguém nunca me perguntou. E por isso também nunca precisei responder. Não posso dizer que nunca tivesse ouvido falar nele, mas a verdade é que não fazia a menor idéia de quem ele era até ler o nome de Buell Quain pela primeira vez num artigo de jornal, na manhã de 12 de maio de 2001, um sábado, quase sessenta e dois anos depois da sua morte às vésperas da Segunda Guerra. O artigo saiu meses antes de outra guerra ser deflagrada. Hoje as guerras parecem mais pontuais, quando no fundo são permanentes. (CARVALHO, 2004, p. 13)

Enquanto, no primeiro trecho, Manoel Perna escreve para alguém que não sabe quem é, nem se um dia chegará a lê-lo, no segundo, o jornalista revela a falta de interesse das pessoas com quem esteve para a investigação em lhe questionar os motivos da investigação. A advertência quanto à instabilidade dos índios e a matéria de jornal com poucos subsídios são dois incômodos. A relatividade do conceito de verdade é a causa das guerras (e do atentado de 11 de setembro aludido pelo narrador). E entre elas, afastadas temporalmente, ambas as guerras são motivadas por não se respeitar à crença e ao espaço alheio. Os homens padecem dos mesmos problemas do mundo moderno: a falta de comunicação, de segurança e de tolerância.

No bojo desses problemas, encontra-se o primeiro daqueles grandes temas da obra de Conrad:

O isolamento, não apenas físico, mas moral (...) impregna a sua obra e é admiravelmente expresso pela circunstância em que se desenvolvem as narrativas do mar e do trópico, utilizadas para estabelecer quase um mito do homem cercado, acuado. Sob este aspecto, há nele um sentimento de ilha que funciona com valor metafórico e alegórico. (...) Daí resulta o sentimento de bloqueio numa situação, cujos limites traçam superfícies exíguas, forçando o homem a defrontar de maneira crítica o semelhante ou ele próprio. (CANDIDO, 2000, p. 6263)

Os narradores servem-se da história do antropólogo para tomarem lições para si. Em circunstâncias diferentes, eles também se encontram isolados. Na ficção, a morte de Buell Quain funciona como esta metáfora. Na hora fatídica, ele não se encontra no mar, mas na floresta. Por assim dizer, igualmente cerrado. Mas, como aponta CANDIDO (2000) sobre o mar em Lord Jim, nesse caso, a floresta é a metáfora de uma prisão ainda maior. A misantropia do homem branco é a característica paradoxal do antropólogo. A perda dos sentidos, a loucura o consome, leva a provocar a própria morte o indivíduo, portador de grave 
doença venérea, sexualmente reprimido, afastado da família, dos amigos e dos amores, culturalmente distante dos índios.

Ao analisar o segundo grande tema nos textos conradianos, a ocasião, Antonio Candido faz uma afirmação que procede perfeitamente com o bernardino.

A ocasião é a matriz do acontecimento, e este, apesar do seu relativo descrédito na literatura contemporânea, é alicerce do romance, pois constitui uma das manifestações por excelência das situações humanas. (...) o acontecimento é reposto na sua natureza de coisa acontecida, de fato vivo em relação ao qual vão definir-se os atos e que vai-se ligar concatenadamente com outros acontecimentos.(...) Há nos personagens uma certa predisposição para determinado tipo de acontecimento, que, ao surgir, é realmente ocasião, quase ensejo que baliza o seu destino. Portanto, o fato e a peripécia existem com realidade própria, autônoma; mas têm sentido enquanto ocasiões para o personagem se definir. Na sua obra confluem com grande equilíbrio o acontecer externo e a visão interior. (CANDIDO, 2000, p. 65)

Após alimentar-se da documentação oficial, o narrador-jornalista não se sente satisfeito. Há nele um incômodo provocado pela falta de uma informação de foro íntimo que ele não consegue deslindar. Quando começa a conjecturar sobre a hipótese de uma relação passional para o suicídio, o narrador se permite revelar fatos de sua vida. Ocorre como se o descontrole emocional (em menor grau, evidentemente) se transferisse para ele. A complexa relação com o pai é apresentada através de memórias da infância e dos momentos que precedem a morte do progenitor.

Ao falar dos tempos de meninos, o narrador lembra do seu espanto em conhecer o Xingu, quando o pai, proprietário de terras na região, o levava de férias a bordo de um tecoteco pouco seguro. Para extrair o relato de um velho guerreiro da tribo que hospedara Quain, o narrador volta ao convívio com os índios e pode verificar a situação paradoxal em que vivem duas tribos (tirando como exemplo tantas outras pelo país): o descaso das autoridades responsáveis por índios, e o conseqüente processo de aculturação a estes que foram submetidos; e a contrapartida na manutenção de alguns rituais e hábitos indígenas e no incansável trabalho de alguns antropólogos por essa causa.

Os momentos que precedem a morte do progenitor revestem a narrativa de emoção. A internação do pai inconsciente, destituído de posses pelos sucessivos mal-fadados casamentos, possibilita o reencontro do filho com o pai, anos após um divórcio conturbado com a mãe do narrador. É no hospital que ele conhece o americano apreciador de Lord Jim. O velho é assistido por jovens que lêem para ele as obras em inglês, como uma espécie de consolo, uma vez que não se sabe nenhuma informação sobre ele além do país de origem. A história difusa do também inconsciente vizinho de leito de seu pai desperta o interesse do narrador ao ouvir o velho americano pronunciar um nome que, com o tempo, percebe ser Buell Quain. Ao ler o nome no jornal, o narrador faz a associação. 
A ocasião se presentifica no texto bernardino como uma série de coincidências e de duplicatas. Há os traços que aproximam a biografia do narrador-jornalista com Buell Quain. Os dramas familiares (divórcio dos pais e a relação complicada com os pais), a permanência numa tribo (para eles ambientes hostis). E há os duplos: os dois narradores, os dois velhos internados, os dois leitores das obras em inglês, as duas tribos pesquisadas pelo antropólogo (que se contrapõem), os dois indiozinhos que impressionam o antropólogo americano e o narrador-jornalista, os dois pais do judeu que dá chave do mistério para o narrador, a condição bissexual de Buell Quain.

No romance conradiano, Lord Jim reconstrói sua vida sofrendo toda sorte de perigos, no fundo quer reconstruir sua dignidade após ser expulso da marinha mercante. Esse é o ponto sobre o qual Candido discorre para formular o terceiro grande tema em Conrad: o homem surpreendido.

O homem surpreendido age sem motivo aparente, por uma espécie de descarga brusca e inexplicável, um ato formalmente gratuito, de que decorre, porém, uma segunda etapa, pois é obrigado a se refazer, caso pretenda readquirir o equilíbrio interior. (...) é um ser em crise, submetido a uma prova decisiva de individualidade. A crise decorre em geral do conflito com o grupo, ou os padrões: quem tem alicerce, supera e se reconstrói; quem ano tem se dissolve nas coisas, ou, o que para ele era o mesmo, na banalidade do conformismo social. (CANDIDO, 2000, p. 67-69)

Em Nove noites, numa primeira análise, o homem surpreendido poderia corresponder ao narrador-jornalista em sua ânsia por descobrir a causa do ato suicida. O interesse em solucionar o caso surge quando fatos do passado da personagem são apresentados. Entretanto, essa categoria revela também uma visão do contato do homem com a sociedade. O homem surpreendido seria aquele posto em uma situação de conflito.

Ao homem surpreendido corresponderia a imagem traduzida pelo narradorprovinciano para o amigo Buell Quain. O homem investigado não suporta a situação que tem de enfrentar (a revelação de que será pai) e sucumbe. A idéia da paternidade apavora o antropólogo que formava um triângulo amoroso com uma moça e um amigo. O medo do julgamento das outras pessoas quanto ao fato de não ser casado com ela ou a possibilidade de ter sua homossexualidade descoberta faz com que ele entre em crise. Na floresta, uma vez começado o processo de auto-flagelação, quando se vê coberto de sangue, não tem mais volta e decide se enforcar, isso porque "(...) em face das condições primitivas impostas pelos países exóticos, o civilizado se encontra entregue a si mesmo, e se não possuir forças interiores suficientes desmorona, pela ausência do amparo grupal.” (CANDIDO, 2000, p. 70)

Antonio Candido (2000) segue sua análise de Lord Jim, propondo que, conteúdo e forma não se dissociam nessa obra. A forma está a serviço do conteúdo e daí se explica a 
divisão da narrativa em duas sequiências, em que cada uma corresponderia a um estágio na vida do protagonista. Além disso, os temas postos convergiriam na prefiguração de um homem fragmentário. Percebe-se, então, que, escrita no último ano do século XIX, a obra de Conrad antecipa o pós-modernismo.

O pós-modernismo, que não deseja ser revolucionário, não se fundamenta mais num mito colocado no futuro: o mito do homem, da sociedade e da cidade modernos. Ao contrário, uma vez que a sociedade pós-industrial renunciou a todo ideal, o pós-moderno se contentará com uma arquitetura modesta e fragmentária, que misturará os códigos. (...) Contrário aos dogmas da coerência, do equilíbrio e da pureza sobre os quais o modernismo se fundara, o pósmodernismo reavalia a ambigüidade, a pluralidade e a coexistência dos estilos; cultiva ao mesmo tempo a citação vernácula e a citação histórica. A citação é a mais poderosa figura pósmoderna. (COMPAGNON, p. 109)

Através da personagem do velho americano internado, incapaz de assumir seu relacionamento amoroso com Buell Quain, mais ainda à espera dele décadas depois, que ouve a exaustiva leitura de Lord Jim, a história do homem incapaz de assumir seu erro e à espera do momento exato para a reação, Bernardo Carvalho recria a metáfora do homem moderno ilhado e surpreendido.

Além dos antropólogos da narrativa, Nove noites apresenta um autor-antropólogo, cuja construção das personagens não visa só à características psicológicas ou físicas, mas sóciohistóricas, culturais e comportamentais. Homem bernardino é um homem por um todo. Esse fenômeno que conjuga ficção e antropologia é descrito por Milton Hatoum, outro autor contemporâneo:

Muitas obras de ficção mantêm certos laços de parentesco com a antropologia, e é provável que um romancista seja, em vários casos, um antropólogo imaginoso, livre de amarras teóricas e de estudos de campo. Esse grau de parentesco é variado, mas alguma coisa essencial une o estudo antropológico ao texto de ficção: ambos falam do Outro e elaboram um discurso sobre a identidade. (HATOUM, 2004, p 135)

A existência de dois narradores no romance bernardino por si só não conferiria a obra especial destaque, não fosse o modo como eles se aproximam e se refutam, apropriando-se de diferentes estratégias discursivas ou estabelecendo perspectivas divergentes sobre um mesmo fato. Além disso, aqui a identidade individual em destaque não é uma, mas são três: a dos dois narradores e a do sujeito sobre o qual recai a atenção deles. E a identidade coletiva que se projeta é a do homem moderno, envolto em uma série de situações-limite. É importante que se comece a olhar o conceito de identidade também para além da nacional. 


\section{Referências}

CANDIDO, Antonio. Tese e antítese: ensaios. 4. ed. São Paulo: T. A. Queiroz, 2000.

CARVALHO, Bernardo. Nove noites. $3^{\mathrm{a}}$. reimpr. São Paulo: Companhia das Letras, 2004.

COMPAGNON, Antoine. Os cinco paradoxos da modernidade. $2^{\mathrm{a}}$. reimpr. Belo Horizonte: Editora UFMG, 2003.

CONRAD, Joseph. Lord Jim. Tradução QUINTANA, Mário. São Paulo: Abril Cultural, 1982.

GEERTZ, Clifford. O mundo em pedaços: cultura e política no fim do século: In: Nova luz sobre a antropologia. Rio de Janeiro: Jorge Zahar, 2001.

HATOUM, Milton. Laços de parentesco: ficção e antropologia. In: PEIXOTO, Fernanda Áreas, PONTES, Heloisa \& SCHWARZ, Lilia Moritz (orgs.) Antropologias, histórias, experiências. Belo Horizonte: UFMG, 2004.

LAUB, Michel. Entrevista com Bernardo Carvalho. Entrelivros. n. 13. ano 2. São Paulo: Duetto Editorial Ltda. p. 20-25. 2006.

PERRONE-MOISÉS, Leyla. Altas literaturas: escolha e valor na obra crítica de escritores modernos. São Paulo: Companhia das Letras, 1998.

SZALBOLCSI, Miklós. Literatura universal do século XX: principais correntes. Tradução JOVANOVIC, Aleksandar. Brasília: EdUNB, 1987. 